\title{
PRONOMES NULOS NA POSIÇÃO DE SUJEITO NO PORTUGUÊS DE ANGOLA - UM ESTUDO PRELIMINAR*
}

\author{
Márcia Santos Duarte de Oliveira \\ Eduardo Ferreira dos Santos**
}

RESUMO: Neste artigo, apresentamos um estudo preliminar - centrado em dados obtidos em Chavagne (2005) - de pronomes na posição de sujeito no português falado de Angola (PA). Enfocam-se a presença/ausência de pronomes na posição de sujeito nessa variante do português africano, visando a uma comparação inicial com dados do português brasileiro (PB) e do europeu (PE). A literatura aponta que o português brasileiro moderno vem atestando uma redução de ocorrência de sujeitos pronominais nulos, diferenciando-se, neste aspecto, do PE. A análise dos dados de PA, no tocante ao Parâmetro do Sujeito Nulo, inclui essa variante do português dentro das línguas de sujeito nulo, como o PE. No entanto, ao voltarmos nossa atenção para as primeiras pessoas do singular e do plural, o PA apresenta uma característica que o aproxima do PB, ou seja, o preenchimento da posição de sujeito ligado à hierarquia da referencialidade, como apontado em Cyrino, Duarte \& Kato (2000).

PALAVRAS-CHAVE: Pronomes na posição de sujeito; parâmetro do sujeito nulo; português de Angola; português do Brasil; português europeu.

\footnotetext{
Este artigo é resultado da pesquisa de Iniciação Científica desenvolvida por Eduardo F. dos Santos (2006/2007) com bolsa de Iniciação concedida por CNPq. A pesquisa foi orientada pela Profa. Dra. Márcia Santos Duarte de Oliveira - DLCV (AFLP) - FFLCH/USP. - Universidade de São Paulo.
} 
OLIVEIRA, Márcia Santos Duarte de e SANTOS, Eduardo Ferreira dos. Pronomes nulos na...

\section{INTRODUÇÃO}

( ste artigo, centrado em dados de uma variante do português africano - a angolana -, insere-se no projeto CAPES/ COFECUB n 511/2005: A participação das línguas africanas na constituição do português brasileiro. Nesse projeto, planeja-se o estudo comparativo da influência das línguas africanas sobre os crioulos de base portuguesa e sobre o português falado na África, para se proceder a uma real comparação deste último com o português falado no Brasil.

O objetivo central do nosso estudo é investigar dados do português falado em Angola - enfocando os pronomes nulos em posição de sujeito nessa variante -, a fim de compará-los, principalmente, com o português do Brasil (PB), que apresenta nítidas diferenças do português europeu no que concerne à organização da categoria pronominal sem matriz fonética. Entendemos por PB, neste trabalho, a norma culta falada da região sudeste do país, ou seja, a área que compreende as cidades do Rio de Janeiro e de São Paulo. Para mais pormenores sobre essa realidade linguiística, ver Ilari et al. (1996).

Nos capítulos a seguir, apresentamos os resultados da pesquisa "Pronomes nulos na posição de sujeito no português de Angola", centrada em dados do português de Angola, obtidos em Chavagne (2005). O trabalho está dividido em quatro capítulos além deste introdutório. No segundo capítulo, resumimos o arcabouço teórico em que se baseia nossa análise dos dados. O terceiro capítulo objetiva apresentar os resultados da pesquisa: (i) comparação do quadro pronominal em posição de sujeito no português de Angola (PA) aos quadros pronominais do português europeu (PE) e brasileiro (PB), (ii) o parâmetro do sujeito nulo em PA, comparado ao PE e PB. Os capítulos quatro e cinco são dedicados à conclusão e à referência bibliográfica, respectivamente. 


\section{CONSIDERAÇÕES SOBRE O ARCABOUÇO TEÓRICO EM QUESE BASEIA O ESTUDO}

Este artigo apresenta resultados de pesquisa de Iniciação Científica que visa a contribuir para uma comparação inicial, no que concerne a pronomes nulos na posição de sujeito, entre o português de Angola (daqui em diante, PA) e duas outras variantes do português: a brasileira (daqui em diante, $\mathrm{PB}$ ) e a européia (daqui em diante, PE). Foi nosso objetivo verificar se pronomes na posição de sujeito em PA comportam-se como a variedade do PB ou como a variedade do PE.

A literatura atesta que o PB moderno vem apresentando uma redução de ocorrência de sujeitos pronominais nulos, diferenciandose, nitidamente, neste aspecto, do PE, como apresentamos a seguir.

\section{1. A Teoria Gerativa e o Parâmetro do Sujeito Nulo}

Segundo a teoria chamada "Gramática Gerativista (GG)" em seu modelo de Princípios \& Parâmetros - ver Chomsky (1981) -, a possibilidade de falar línguas é uma capacidade inata do homem. Logo, o foco de estudo dessa teoria é a chamada língua interna ou competência do indivíduo.

A GG prevê Princípios e Parâmetros, sendo os Princípios determinados pela Gramática Universal, ou estado mental inicial, e os Parâmetros postulados pela variação entre as línguas. Todas as diferenças entre as línguas particulares são limitadas pelo Princípio que governa cada Parâmetro. Um dos Parâmetros mais estudados dentro desse arcabouço teórico é o Parâmetro do Sujeito Nulo - daqui em diante, PSN - e que diz respeito, principalmente, ao preenchimento da posição de sujeito.

A língua portuguesa é conhecida na literatura como "língua pro-drop" (de sujeito nulo), diferentemente, por exemplo, do inglês, dita uma "língua não pro-drop" (de sujeito não nulo). Pesquisas sobre o sistema pronominal na variedade PB vêm demonstrando que o PSN está sofrendo uma mudança nessa variedade: um decrés- 
OLIVEIRA, Márcia Santos Duarte de e SANTOS, Eduardo Ferreira dos. Pronomes nulos na...

cimo de ocorrência de sujeitos nulos. Observe os dizeres de Quint (no prelo):

[...] os dados apontam para um aumento contínuo do preenchimento da posição de sujeito em PB desde o século XIX até hoje (cf. Tarallo 1996: 48; Duarte 1996:112). Logo, expressões do tipo eu canto, ele canta (com pronomes sujeitos pré-verbais) tendem a prevalecer sobre as formas de sujeito nulo canto, canta. A análise de produções orais contemporâneas de diversos grupos etários apresenta resultados comparáveis: as gerações mais jovens é que mais frequientemente usam pronomes sujeitos pré-verbais (Duarte, 2000, p. 20-2).

Segundo Oliveira \& Quint (2005, p. 2-3), citando Cyrino, Duarte $\&$ Kato (2000), o PB moderno exibe pronomes sujeitos plenos onde um pronome não preenchido fonologicamente seria esperado em línguas de sujeito nulo: ${ }^{1}$

(1) a. Eu estou doente.

b. O Carlos ${ }_{\mathrm{i}}$ disse que ele ${ }_{\mathrm{i}}$ está doente.

c. [A Rainha da Inglaterra] ${ }_{\mathrm{i}}$ disse que ela ${ }_{\mathrm{i}}$ quer seu filho divorciado.

- Em PB, construções com sujeito nulo podem também aparecer:

no lugar de construções indefinidas em PE com o clítico se e a forma verbal de terceira pessoa do singular: ${ }^{2}$

(2) a. No Brasil, circula-se à direita. (PE)

b. No Brasil, circula à direita. (PB)

(ii) caso o sujeito seja arbitrário: ${ }^{3}$

(2) a. A gente no Brasil circula à direita.

b. No Brasil você circula à direita.

1 Cyrino, Duarte \& Kato (2000, p. 59). Dados [8a,b,c.], renumerados

Idem, p. 60. Dados [9a, b], renumerados.

Idem, p. 60. Dados (10a, b), renumerados. 
Inicialmente, justificou-se o decréscimo da ocorrência de sujeitos nulos em PB ao paradigma flexional nesta língua, como defende Duarte (1993). No entanto, explicar (dentro do arcabouço gerativista) o PSN atrelando-o à flexão tornou-se um problema após o trabalho de Huang (1984) sobre o chinês, pois essa língua permite a queda do sujeito, embora não manifeste qualquer tipo de flexão.

Cyrino, Duarte e Kato (2000, p. 59) apresentam uma proposta explicativa para a redução de sujeito nulo em PB. Para as autoras (op. cit.), o processo de pronominalização nessa variedade do português parece estar sendo guiado pela hierarquia de referencialidade e pelo mapeamento implicacional:4 "Quanto mais referencial, maior a possibilidade de um pronome não nulo."

Segundo Oliveira \& Quint (2005, p. 4), que retomam a proposta de Cyrino, Duarte e Kato (2000):

[...] cross-lingüisticamente, a referencialidade é altamente relevante para a pronominalização. Para uma língua que tem a opção interna de pronome pleno ou variante nula, como PB, um dos fatores que influenciam na escolha de uma ou outra forma é o status referencial do antecedente.

- O traço [+ Humano]

De acordo com a hipótese de Cyrino, Duarte \& Kato (2000, p. 59), os argumentos [+N, + Humano] são os mais altos na hierarquia referencial, enquanto não argumentos são os mais baixos. Para pronomes, haja vista que o falante ("eu") e o receptor ("você") são inerentemente humanos, a primeira e segunda pessoa são as mais altas na hierarquia, enquanto a terceira que refere-se a proposições é a mais baixa, com a entidade [animada] entre elas. $O$ traço [ $\pm \partial$ específico] interage com todos os outros traços.

4 A proposta de "hierarquia de referencialidade em PB", apresentada acima, não está atrelada apenas à explicação do aumento do preenchimento da posição de sujeito em $\mathrm{PB}$, mas permite ainda às autoras (op. cit.) explicarem os contrastes demonstrados entre os pronomes sujeito e objeto em PB. Essa variedade está se tornando uma língua de sujeito não nulo, mas também uma língua de objeto nulo - um fato linguiístico nomeado pelas autoras como o "quebra-cabeça de Tarallo (1983)". Na pesquisa, e neste trabalho, o parâmetro "pro-drop" atrelado ao objeto não é abordado. 
OLIVEIRA, Márcia Santos Duarte de e SANTOS, Eduardo Ferreira dos. Pronomes nulos na...

Logo, segundo Cyrino, Duarte \& Kato (2000), parece que PB está evitando o aparecimento de expressões nulas na posição de sujeito com antecedentes [+ humano]. ${ }^{5}$

No próximo capítulo, apresentam-se os principais resultados da pronominalização enfocando a posição do sujeito em PA, visando a uma comparação inicial com o PB e PE que atestam comportamentos distintos no tocante ao PSN.

\section{PRONOMES LIVRES EM POSIÇÃO DESUJEITO EM PA}

Neste capítulo, abordamos os principais resultados obtidos ao longo de nossa pesquisa: (i) uma proposta sobre o quadro pronominal do PA na posição de sujeito, (ii) aspectos do Parâmetro do Sujeito Nulo nessa variante do português na África.

\section{1. Pronomes na Posição de Sujeito em PA - Comparações com o PE e PB}

Na pesquisa que resultou neste trabalho, centrada no corpus apresentado no Anexo 1, comparamos o preenchimento da posição de sujeito no PA com as variedades do PB e PE. Porém, antes da apresentação dos resultados parciais do preenchimento do sujeito em PA, apresentamos o levantamento parcial do quadro pronominal do PA na posição de sujeito, comparado a quadros do PB e do PE.

A partir da delimitação e organização dos dados, a fim de se verificar o Parâmetro do Sujeito Nulo em PA, percebemos a importância de destacarmos, preliminarmente, o "possível" quadro pronominal desta variante do português. Logo, procedemos a uma descrição preliminar do quadro de pronomes livres na posição de sujeito em PA, já que este quadro visava a apontar as formas prono-

Segundo Cyrino, Duarte \& Kato (2000), esta mesma hierarquia de referencialidade explica o acréscimo de objetos nulos com antecedentes [-humano] em PB. No entanto, como já menciona nota 9 , o tratamento do objeto está fora do escopo desse trabalho. 
minais em uso e serviria de apoio para a identificação do preenchimento ou não da posição de sujeito.

Abaixo, apresentamos o quadro dos pronomes na posição de sujeito em PA:

\section{Quadro 1: Pronomes livres na posição de sujeito em PA}

\begin{tabular}{|c|c|}
\hline PESSOA & FORMAS \\
\hline 1sg & Eù \\
\hline $2 \mathrm{sg}$ & Tu-Você \\
\hline 3sg & Ele-Ela \\
\hline $1 \mathrm{pl}$ & Nós - Agente \\
\hline $2 \mathrm{pl}$ & Vocês \\
\hline $3 \mathrm{pl}$ & Eles \\
\hline
\end{tabular}

Antes de exemplificarmos os pronomes livres na posição de sujeito em PA vistos no quadro 1 (que faremos na seção 3.1.1.), apresentamos os quadros de pronomes livres na posição de sujeito em $\mathrm{PE}$ e $\mathrm{PB}$, a fim de procedermos a uma comparação com o quadro 1 do PA.

Quint (no prelo) - por meio de uma comparação de paradigmas verbais em latim, galego, $\mathrm{PE}$ e $\mathrm{PB}^{6}$ - nos permite levantar um quadro dos pronomes livres em posição de sujeito em PE. Segundo o autor (o grifo é nosso):

i) o PE, tal como é falado hoje em dia, só apresenta cinco formas pessoais sintéticas, tendo passado a forma derivada da $3^{\mathrm{a}}$ pessoa do plural latina a ser usada também quando o sujeito é de $2^{\mathrm{a}}$ pessoa do plural. 0 uso de pronomes pessoais (i. e. (vocês) cantam vs. (eles) cantam) é que permite resolver os casos de ambiguiidade;

6 Quint (no prelo) compara paradigmas verbais do presente do indicativo do verbo cantar(e) em latim, galego, PE e PB. Segundo o autor (op. cit.), a análise das flexões neste tempo verbal basta, em geral, para apresentar uma idéia das distinções de pessoa em quase todas as línguas românicas. 
OLIVEIRA, Márcia Santos Duarte de e SANTOS, Eduardo Ferreira dos. Pronomes nulos na...

Logo, seguindo Quint (op. cit.), podemos levantar o quadro pronominal na posição de sujeito do PE:

Quadro 2: Pronomes livres na posição de sujeito em PE

\begin{tabular}{|cc|}
\hline PESSOA & FORMAS \\
\hline $1 \mathrm{sg}$ & Eu \\
\hline $2 \mathrm{sg}$ & Tu \\
\hline $3 \mathrm{sg}$ & Ele - Ela \\
\hline $1 \mathrm{pl}$ & Nós \\
\hline $2 \mathrm{pl}$ & Vocês \\
\hline $3 \mathrm{pl}$ & Eles - Elas \\
\hline
\end{tabular}

A seguir. Apresentamos os pronomes livres na posição de sujeito em PB, de acordo com Ilari et al., 1996, p. 83): ${ }^{7}$

Quadro 3: Pronomes livres na posição de sujeito em PB

\begin{tabular}{|cc|}
\hline PESSOA & FORMAS \\
\hline $1 \mathrm{sg}$ & Eu \\
\hline $2 \mathrm{sg}$ & $\begin{array}{c}\text { Você } \\
\text { Osenhor }- \text { A senhora }\end{array}$ \\
\hline $3 \mathrm{sg}$ & Ele - Ela \\
\hline $1 \mathrm{pl}$ & Nós - A gente \\
\hline $2 \mathrm{pl}$ & Vocês $^{8}$ \\
\hline $3 \mathrm{pl}$ & Eles - Elas \\
\hline
\end{tabular}

A partir dos quadros 1, 2 e 3 acima (pronomes livres na posição de sujeito em PA, PE e PB), apontamos as seguintes semelhanças entre as três variantes do português:

7 Baseamo-nos no quadro 1 dos autores (op. cit.), no entanto considerando apenas as cidades do Rio de Janeiro e São Paulo.

8 No quadro apresentado por llari et al. (1996), não aparece a forma "vocês". No entanto, segundo o autor, a forma "vocês" é a junção da idéia de uma 2a + 2a pessoa, e também uma 2a + 3a pessoa (op. cit., p. 98). 
Filol. lingüíst. port., n. 9, p. 85-101, 2007.

Semelhanças PA, PE, PB

$$
\begin{aligned}
& 1 \mathrm{sg} \text { - EU } \\
& 3 \mathrm{sg}-\mathrm{ELE} / \mathrm{ELA} \\
& 1 \mathrm{pl}-\mathrm{NÓS} \\
& 2 \mathrm{pl}-\mathrm{VOCÊS} \\
& 3 \mathrm{pl}-\mathrm{ELES} / \mathrm{ELAS}
\end{aligned}
$$

Semelhanças PA, PB

$$
\begin{aligned}
& 2 \mathrm{sg} \text { - VOCÊ } \\
& 1 \mathrm{pl}-\mathrm{A} \text { GENTE }
\end{aligned}
$$

\section{Semelhanças PA, PE}

$$
2 \mathrm{sg}-\mathrm{TU}
$$

Pelo exposto acima, o PA aproxima-se do PB no tocante a $2 \mathrm{sg}$ e $1 \mathrm{pl}$, por meio das formas "você" e "a gente". No entanto, os dados apontam o uso do pronome de $2 \mathrm{sg}$ "tu" demonstrando uma alternância "tu/você".

\subsubsection{Exemplos de pronomes livres na posição de sujeito em PA9}

EU:

(1) Uma coisa muito curiosa, EU sei que tu vieste de Cabinda. Foi muito fácil adaptares a viver aqui?

(2) EU gosto de fazer leituras...

TU:

(3) Uma coisa muito curiosa, eu sei que TU vieste de Cabinda. Foi muito fácil adaptares a viver aqui?

9 Dados de Santos (2006), renumerados. 
OLIVEIRA, Márcia Santos Duarte de e SANTOS, Eduardo Ferreira dos. Pronomes nulos na...

VOCÊ:

(4) Mesmo assim, há uma comparação entre a sua forma o aqui VOCÊ trabalha, pode às vezes conseguir dinheiro. Nota nas crianças a mesma facilidade?

\section{ELE/ELA}

(5) Bem, vamos lá supor que haja dificuldade e ELE vai pagar nota verde.

(6) ELA é muito a minha amiga. Geni tá tudo bem?

(7) Quer dizer ELE é um jogador, consegue, consegue de mudar o resultado em vinte e quatro segundos.

(8) Por acaso eu não acho. Eu acho que matemática quando bem entendida, ELA é boa.

NÓS

(9) Vamos lá conversar um bocadinho com o Chefe. É verdade, Chefe, aqui no lar NÓS sabemos que o teu nome é Rodino, (...) te chamam de Chefe. Porquê?

(10) Quer dizer ainda não conseguimos mas como tem aqui uma bola da escola e o detector também sabe que NÓS gostamo de jogar basquete e ele (...) daquela bola e (...) semana.

\section{A GENTE}

(11) Eu acho que mudou muito Eu não vou falar do Benfica passado. Actualmente fala-se, se trata ou melhor, dum Benfica muito modelado em muitos aspectos, por isso tou aqui muito apostado na equipe especialmente este ano, este ano porquê independente de mim também é o último ano para mim, já que afinal de conta A GENTE como jogadores temos que pensar hm num progresso e Benfica é uma equipe da segunda divisão como sempre foi, né?, e eu tenciono, quem sabe?, por ano estar uma das grandes equipas assim como da primeira divisão. 


\section{VOCÊS}

(12) Há uma outra coisa que é muito curiosa. É o primeiro ano que VOCÊS estão a enfrentar o ensino médio e ao mesmo tempo estão a trabalhar. Conseguem reconciliar as duas coisas?

(13) Para além do basquetebol, qual é a outra coisa que VOCÊS praticam aqui?

(14) E há uma outra questão: VOCÊS geralmente vivem assim em grupo com pessoas que gostam de praticar modalidades. A São também gosta? Pelo menos os rapazes ali disseram que gostam muito de basquete. A São?

\section{ELES}

(15) $($...) as greves estão a se registar não só (...) fazem essa greve devido problema de salários de (...) tem ELES pretendem que lhes façam aumento

(16) Eh pá me chamam de chefe, portanto, de princípio sou uma pessoa muito animadora talvez digamos assim né? E quando cheguei aqui portanto eu saí do Tchivinguiro para aqui é pá digo bem melhor chefe porque de princípio os outros de chefe. Chefe, chefe, pronto ELES também agora me meteram o nome de chefe.

\section{1.2. Parâmetro do Sujeito Nulo emPA}

Antes de tratarmos do PSN em PA, vale ressaltar, aqui, como consideramos, a partir da reorganização e delimitação dos dados, ${ }^{10}$ as situações que nos ajudaram a verificar o preenchimento ou não de pronomes em posição de sujeito nessa variante.

Observe o dado abaixo: ${ }^{11}$

10 Santos (2006). Reorganização dos dados do Anexo 1 de Chavagne (2005) em 369 sentenças com contexto de verificação do PSN.

11 Santos (2006). Dado (19), renumerado. 
OLIVEIRA, Márcia Santos Duarte de e SANTOS, Eduardo Ferreira dos. Pronomes nulos na...

(17) Eh pá me CHAMAM de chefe, portanto, de princípio SOU uma pessoa muito animadora talvez DIGAMOS assim né? E quando CHEGUEI aqui portanto EU saí do Tchivinguiro para aqui é pá DIGO bem melhor chefe porque de princípio os outros de chefe. Chefe, chefe, pronto ELES também agora me meteram o nome de chefe.

Nós observamos o preenchimento da posição de sujeito a partir da presença/ausência das formas pronominais. Logo, para o dado (17) acima, temos:

- duas situações de sujeito pronominalmente preenchido EU saí do Tchivinguiro

ELES também me meteram (...)

- cinco situações de sujeito nulo (marcadas com um tracejo) me _ CHAMAM de chefe (...)

_. SOU uma pessoa muito animadora (...)

Talvez _ DIGAMOS assim né?

Quando _ CHEGUEI aqui (...)

_ DIGO bem melhor chefe (...)

Utilizando-se desse critério em todas as 369 sentenças consideradas para o nosso corpus, chegamos ao seguinte resultado apontado no quadro a seguir: 
Quadro 4: Número de ocorrências das formas pronominais na posição de sujeito em PA em 369 sentenças - cf. Santos (2006)

\begin{tabular}{|ccc|}
\hline PRONOME & PREENCHIDO & NULO \\
\hline Eu & 87 & 198 \\
\hline Tu & 1 & 17 \\
\hline Você & 1 & 140 \\
\hline Ele/Ela & 10 & 11 \\
\hline Nós & 38 & 59 \\
\hline A gente & 1 & - \\
\hline Vocês & 7 & 13 \\
\hline Eles/Elas & 2 & 6 \\
\hline
\end{tabular}

O resultado da pesquisa, observando o quadro 4 acima, aponta que o PA, como o PE e o PB, apresentam a opção de preenchimento/não-preenchimento do sujeito. No entanto, como já apontado no capítulo 2, o PB parece estar caminhando para uma mudança do parâmetro, em que a posição de sujeito encontra-se cada vez mais preenchida. Logo, nesta pesquisa, interessou-nos verificar se o PA encontra-se mais próximo à variante $\mathrm{PE}$, no tocante ao $\mathrm{PSN}$, ou mais próximo à variante $\mathrm{PB}$. Abaixo, sintetizamos o $\mathrm{PSN}$ em $\mathrm{PE}$ e $\mathrm{PB}$ :

\footnotetext{
Língua portuguesa e o Parâmetro do Sujeito Nulo Variante PE - posição de sujeito preferencialmente nulo;

Variante PB - posição de sujeito preferencialmente preenchido nos contextos em que o sujeito é mais referencial - ver Cyrino, Duarte \& Kato (2000) e resenha das autoras no capítulo 2.
}

Logo, a partir do quadro 4, e do resumo do PSN em PE e PB acima, percebemos que o PA, no tocante ao PSN, está próximo à variante PE: o não-preenchimento da posição de sujeito é o mais recorrente nos dados. Na tabela 4, exceto com as formas pronominais livres $1 \mathrm{sg} / \mathrm{pl}$, todas as formas pronominais sujeito apresentam tendência a serem não preenchidas. Porém, é importante ressaltar um fato apreendido ainda na tabela 4: a alta frequiência de preenchimento do sujeito de $1^{\text {a }}$. pessoa, como destacamos na subseção abaixo. 
OLIVEIRA, Márcia Santos Duarte de e SANTOS, Eduardo Ferreira dos. Pronomes nulos na...

\section{1.2. 1. Pronome de 19. Pesson em PA e o PSN}

A seguir, retomamos a tabela 4 enfocando apenas o PSN relacionado às formas pronominais livres $1 \mathrm{sg} / \mathrm{pl}$ :

Quadro 5: Número de ocorrências de formas pronominais livres $1 \mathrm{sg} / \mathrm{pl}$ na posição de sujeito em PA

\begin{tabular}{|ccc|}
\hline PRONOME & PREENCHIDO & NULO \\
\hline Eu & 87 & 198 \\
\hline Nós & 38 & 5 \\
\hline
\end{tabular}

A tabela em 5 é significativa para nossa pesquisa ao compararmos o PSN em PA ao PSN em PB. Em PB, o aumento no preenchimento da posição de sujeito tem sido explicado por meio da hierarquia de referencialidade: "Quanto mais referencial, maior a possibilidade de um pronome não nulo." (Cyrino, Duarte \& Kato, 2000, p. 59).

Logo, embora o PSN em PA siga o padrão de sujeito nulo do $\mathrm{PE}$, como demonstrado na tabela 4 , a tabela 5 indica que, na variante PA, os pronomes de primeira pessoa (singular e plural) começam a aproximar-se do PB: preenchimento da posição de sujeito. Em outras palavras, o PA apresenta indícios de estar caminhando em direção ao preenchimento da posição de sujeito guiado pela hierarquia de referencialidade.

\section{N. CONCLUSÃO}

Neste artigo, resultado da pesquisa "Pronomes nulos na posição de sujeito no português de Angola”, enfocamos (i) uma proposta sobre as formas pronominais sujeito do PA, (ii) aspectos do Parâmetro do Sujeito Nulo nessa variante do português falado na África.

A partir da reorganização e delimitação dos dados do corpus, levantamos o quadro pronominal do português angolano (PA) em 
relação ao sujeito, no qual foi possível realizarmos uma comparação entre essa variante e as variantes do português europeu (PE) e do português brasileiro (PB). Os resultados dessa comparação mostraram que o PA apresenta pronomes livres na posição de sujeito semelhantes às variantes européia e brasileira. $\mathrm{O}$ que nos chamou a atenção foi a realização das formas "você" para a $2^{\mathrm{a}}$ pessoa do singular e "a gente" para a $1^{\text {a }}$ pessoa do plural, também encontradas no PB. No PA também encontramos a forma "tu" para a $2^{\mathrm{a}}$ pessoa do singular, identificada no PE, mas inexistente em PB (na área do sudeste do Brasil). A forma "vós", reservada à $2^{\mathrm{a}}$ pessoa do plural, não foi identificada no nosso corpus e não foi relacionada no quadro de pronomes pessoais na posição de sujeito para o português brasileiro, de Ilari et al. (1996), assim como parece estar em desuso na variante européia do português atual.

Quanto a um dos aspectos do parâmetro do sujeito nulo preenchimento/ não-preenchimento da posição de sujeito -, concluímos que o PA apresenta-se como uma língua de sujeito nulo, como o PE e o PB. No entanto, ao voltarmos nossa atenção para a primeira pessoa do singular e do plural, o PA apresenta uma característica que o aproxima do PB: o preenchimento da posição de sujeito ligado à hierarquia da referencialidade.

Consideramos que este trabalho, embora de caráter preliminar, aponta novos caminhos de pesquisa que se relacionam à investigação e ampliação do tema PSN no português de Angola, como: (i) a investigação da hierarquia de referencialidade em PA ligada aos pronomes livres em posição de objeto; (ii) outras características do PSN nessa variante, como, por exemplo, a possibilidade de inversão do sujeito, permitida em $\mathrm{PE}$, mas não em $\mathrm{PB}$. 
OLIVEIRA, Márcia Santos Duarte de e SANTOS, Eduardo Ferreira dos. Pronomes nulos na...

\section{BIBLIOGRAFIA}

AUGUSTO, M. R. A; SCHER, A. P.; BERLINCK, R. de A. (2004) Sintaxe. In: MUSSALIM, F; BENTES, A. C. (orgs.) Introdução à lingüística: domínios e fronteiras. São Paulo: Cortez, v.1 . CHAVAGNE, J-P. (2005) La langue portugaise d'Angola - etude des écarts par rapport à la norme europénne du portugais. Thèse (Doctorat) - Université Lumière. Lyon 2.

CYRINO, S. M.; DUARTE, M. E; KATO, M. A. (2000) Visible subjects and invisible clitics in Brazilian Portuguese. In: KATO, M. A.; NEGRÃO, E. V. (eds.). Brazilian Portuguese and the null subject parameter. Frankfurt am main: Vervuert.

DUARTE, M. E. L. (1996) Do pronome nulo ao pronome pleno: a trajetória do sujeito no português do Brasil. In: ROBERTS, I.; KATO, M. A. (orgs.). O português brasileiro: uma viagem diacrônica. Campinas: Editora da Unicamp.

HAEGEMAN, L. (1999) Introduction to government and binding theory. 2. ed. Oxford: Blackwell.

ILARI, R. et al. (1996) Os pronomes pessoais do português falado: roteiro para a análise. In: CASTILHO, A. T. de; BASÍLIO, M. (orgs.). Gramática do português falado. Campinas: Editora da Unicamp; São Paulo: Fapesp, v. IV: Estudos descritivos.

MATTOSO CÂMARA JR., J. (1972) Ele como um acusativo no Português do Brasil. In: UCHOA, C.E.F. (sel. e introdução). Dispersos de J. Mattoso Câmara Jr. Rio de Janeiro: Fundação Getúlio Vargas, p. 47-53.

MIOTO, C. et al. (2005) Novo manual de sintaxe. 2. ed. Florianópolis: Insular.

NEGRÃO, E. V. Brazilian Portuguese as discourse-oriented language (2000) In: KATO, M. A.; NEGRÃO, E. V. (ed.). Brazilian Portuguese and the null subject parameter. Frankfurt am main: Vervuert, p. 105-25.

OLIVEIRA, M. S. D; QUINT, N. (2005) Para uma investigação de traços da sintaxe pronominal de línguas africanas na constituição do português brasileiro. Seminário apresentado no $1^{\circ}$ Encontro dos Pesquisadores do Projeto CAPES/COFECUB. Departamento de Linguíística da Universidade de São Paulo. Manuscrito.

QUINT, N. O. (no prelo) O preenchimento da posição de sujeito em português do Brasil: deriva versus crioulização.

SANTOS, E. F. dos. (2006) Reorganização do corpus de Chavagne (2005 - Anexo 1). Manuscrito. TARALLO, F. (1996) Diagnosticando uma gramática brasileira: o português d'aquém e d'alémmar ao final do século XIX (Fernando Taralo - 1951-1992). In: ROBERTS, I.; KATO, M. A. (orgs.). $O$ português brasileiro: uma viagem diacrônica. Campinas: Editora da Unicamp.

ABSTRACT: In this article we present a preliminary study of pronouns in subject position in the Portuguese of Angola (PA), based on data obtained in Chavagne (2005). The focus of our analysis is the presence/absence of pronouns in this variant of African Portuguese, aiming at an initial comparison with data of Brazilian Portuguese (BP) and of European Portuguese (EP). It has been pointed out in the literature that BP shows a reduction in the occurrence of null pronouns in subject position, differing in this respect from EP. The analysis of the PA data concerning the Null 
Filol. lingüíst. port., n. 9, p. 85-101, 2007.

Subject Parameter includes this variant of Portuguese as a null subject language, olike EP. However, like BP but unlike Ep, Portuguese fills the first person singular and plural in the subject position more than in the other persons. In Brazilian Portuguese, this phenomenon was describe in Cyrino, Duarte \& Kato (2000).

KEYWORDS: Pronouns in subject position; null subject parameter; Portuguese of Angola; Brazilian Portuguese; European Portuguese. 